\title{
Characterization of a critical role for CFTR chloride channels in cardioprotection against ischemia/ reperfusion injury
}

\author{
Sunny Yang XIANG ${ }^{1, \S}$, Linda L YE ${ }^{1}$, Li-lu Marie DUAN ${ }^{1}$, Li-hui LIU ${ }^{1,3}$, Zhi-dong GE ${ }^{2}$, John A AUCHAMPACH ${ }^{2}$, Garrett J GROSS ${ }^{2}$ \\ Dayue Darrel DUAN ${ }^{1, *}$ \\ ${ }^{1}$ Department of Pharmacology, University of Nevada School of Medicine, Reno, NV 89557, USA; ${ }^{2}$ Department of Pharmacology and \\ Toxicology, Medical College of Wisconsin, Milwaukee, WI 53226, USA; ${ }^{3}$ Institute of Clinical Pharmacology, Central South University \\ Xiangya School of Medicine, Changsha 410078, China
}

Aim: To further characterize the functional role of cystic fibrosis transmembrane conductance regulator (CFTR) in early and late (second window) ischemic preconditioning (IPC)- and postconditioning (POC)-mediated cardioprotection against ischemia/reperfusion (I/R) injury.

Methods: CFTR knockout (CFTR $\left.{ }^{-/-}\right)$mice and age- and gender-matched wild-type $\left(\right.$CFTR $\left.^{+/+}\right)$and heterozygous $\left(\right.$CFTR $\left.{ }^{+/-}\right)$mice were used. In in vivo studies, the animals were subjected to a 30-min coronary occlusion followed by a 40-min reperfusion. In ex vivo (isolate heart) studies, a 45-min global ischemia was applied. To evaluate apoptosis, the level of activated caspase 3 and TdT-mediated dUTP-X nick end labeling (TUNEL) were examined.

Results: In the in vivo I/R models, early IPC significantly reduced the myocardial infarct size in wild-type $\left(\right.$ CFTR $\left.{ }^{+/+}\right)($from $40.4 \% \pm 5.3 \%$ to $10.4 \% \pm 2.0 \%, n=8, P<0.001$ ) and heterozygous $\left(C F T R^{+/-}\right.$) littermates (from $39.4 \% \pm 2.4 \%$ to $15.4 \% \pm 5.1 \%, n=6, P<0.001$ ) but failed to protect CFTR knockout $\left(\mathrm{CFTR}^{-/-}\right)$mice from I/R induced myocardial infarction $(46.9 \% \pm 6.2 \%$ vs $55.5 \% \pm 7.8 \%, n=6, P>0.5)$. Similar results were observed in the in vivo late IPC experiments. Furthermore, in both in vivo and ex vivo I/R models, POC significantly reduced myocardial infarction in wild-type mice, but not in CFTR knockout mice. In ex vivo I/R models, targeted inactivation of CFTR gene abolished the protective effects of IPC against I/R-induced apoptosis.

Conclusion: These results provide compelling evidence for a critical role for CFTR $\mathrm{Cl}^{-}$channels in IPC- and POC-mediated cardioprotection against I/R-induced myocardial injury.

Keywords: ischemia; preconditioning; postconditioning; apoptosis; cystic fibrosis transmembrane conductance regulator (CFTR)

Acta Pharmacologica Sinica (2011) 32: 824-833; doi: 10.1038/aps.2011.61

\section{Introduction}

Ischemia and reperfusion (I/R) induce myocardial injury and lead to infarction through increased apoptosis (programmed cell death) and necrosis ${ }^{[1,2]}$. Ischemic preconditioning (IPC) is a phenomenon in which brief episodes of ischemia dramatically reduce myocardial infarct size produced by a subsequent sustained ischemia and reperfusion ${ }^{[3]}$. IPC has an early phase (lasting 1-2 h) and a late phase or "second window" (lasting 24-72 h) of protection ${ }^{[4]}$. The signaling pathways involved in both early IPC (EIPC) and late IPC (LIPC) have been the

\footnotetext{
${ }^{\S}$ Now in the Department of Pharmacology, University of California at San Diego, 9500 Gilman Drive, La Jolla, CA 92093-0636, USA

${ }^{*}$ To whom correspondence should be addressed.

E-mail dduan@medicine.nevada.edu

Received 2011-03-16 Accepted 2011-04-18
}

subject of numerous intensive studies ever since IPC was first described by Murry et al in $1986^{[5,6]}$. The end-effectors of these signaling pathways are believed to directly participate in protecting the myocardium from subsequent ischemia/ reperfusion insults after $\mathrm{IPC}^{[7-9]}$. Both sarcolemmal and mitochondrial ATP-sensitive potassium channels (sarc- $\mathrm{K}_{\text {ATP }}$ and mito- $\mathrm{K}_{\mathrm{ATP}}$, respectively) have been suggested to serve as mediators or end-effectors in EIPC and LIPC ${ }^{[8,9]}$. Many other factors have also been proposed to be end-effectors, including the mitochondrial permeability transition pore $(\mathrm{mPTP})^{[10]}$, the sodium/hydrogen exchanger ${ }^{[11]}$, and swelling-activated $\mathrm{Cl}^{-}$ channels ${ }^{[12,13]}$. Although it has been shown that specific blockades of each proposed end-effector completely abolish the protection given by IPC, the identification of which factors are true end-effectors and the elucidation of possible interactions between these end-effectors have yet to be established ${ }^{[5,14,15]}$. 
In 2003, Zhao et al reported that short episodes of I/R immediately after sustained ischemia and before full reperfusion reduced myocardial infarct size to a level equivalent to IPC in dogs. This phenomenon was named ischemic postconditioning $(\mathrm{POC})^{[16]}$. POC is as powerful as EIPC and LIPC in reducing myocardial infarction and preserving functional performance of the heart and also has the potential to be clinically applicable in the most common situations of unexpected coronary occlusion and acute myocardial infarction ${ }^{[16-18]}$. To date, POC has been documented in dog, pig, rabbit, rat, and mouse models and in humans ${ }^{[6,16,19-22]}$. This widespread occurrence of POC has aroused a renewed interest in understanding the mechanisms of cell death during I/R and identifying endogenous mediators of cardioprotection against I/ R injury $^{[6,17,18,22,23]}$. Many studies suggest that POC shares some signaling pathways with IPC, including activation of PKC, PKA, PI3K-Akt, and the MEK1/2-Erk1/2 pathways. Both mito-K $\mathrm{K}_{\mathrm{ATP}}$ and $\mathrm{mPTP}$ are also thought to be key players or potential end-effectors in POC ${ }^{[24,25]}$.

A recent study in isolated mouse hearts supports a potential role for the cystic fibrosis transmembrane-conductance regulator (CFTR) in acute $\mathrm{IPC}^{[26]}$. The CFTR gene belongs to the ATP-binding cassette (ABC) transporter superfamily and encodes a PKC- and PKA-activated $\mathrm{Cl}^{-}$channel in the heart $^{[27-30]}$. The sulfonylurea receptor (SUR) and $\mathrm{mABC1}$ are also included in the same ABC superfamily. SUR combines with inward rectifier $\mathrm{K}^{+}$(Kir6.1, Kir6.2) channel subunits to form functional sarc- $\mathrm{K}_{\mathrm{ATP}}$ channels ${ }^{[8,9]}$, and $\mathrm{mABC1}$ was suggested to be a component of mito- $\mathrm{K}_{\mathrm{ATP}}{ }^{[31]}$. While both sarc$\mathrm{K}_{\text {ATP }}$ and mito- $\mathrm{K}_{\text {ATP }}$ channels have been extensively studied for their roles as important mediators of IPC and POC, the relative functional role of cardiac CFTR channels in EIPC, LIPC, and POC has not been studied. This study was designed to directly address this question with CFTR-knockout $\left(\mathrm{CFTR}^{-/-}\right)$ mice and age- and gender-matched wild-type (WT, CFTR ${ }^{+/+}$) and heterozygous $\left(\mathrm{CFTR}^{+/-}\right)$mice.

\section{Materials and methods}

This investigation conforms to the Guide for the Care and Use of Laboratory Animals (US National Institute of Health publication № 85-23, revised 1996) and was carried out in accordance with the Institutional Guidelines for Animal Care and Use approved by the University of Nevada Institutional Animal Care and Use Committee.

\section{Breeding and genotyping of transgenic mice}

STOCKCftrtm1Unc-TgN (FABPCFTR)1Jaw breeders obtained from Dr Jeffrey Whitsett (Children's Hospital Medical Center, Cincinnati, OH, USA) were bred in our transgenic animal facility as previously described ${ }^{[26]}$. Eight- to twelve-week-old male $\mathrm{CFTR}^{-/-}$offspring and age- and gender-matched $\mathrm{CFTR}^{+/+}$and $\mathrm{CFTR}^{+/-}$littermates were used. These mice were genotyped by performing polymerase chain reaction (PCR) on genomic DNA isolated from tail samples using a three-primer assay $\left(5^{\prime}\right.$ GAG AAC TGG AAG CTT CAG AGG-3', 5'-TCC ATC TTG TTC AAT GGC C-3', and 5'-TCC ATG TAG TGG TGT GAA
CG-3'), which resulted in a 357-bp band for CFTR ${ }^{-/-}$, a 526-bp band for $\mathrm{CFTR}^{+/+}$, and both bands for $\mathrm{CFTR}^{+/-}$.

\section{In vivo $\mathrm{I} / \mathrm{R}$ injury}

Mice were anesthetized with sodium pentobarbital $(50 \mathrm{mg} / \mathrm{kg}$, ip), placed on a $37^{\circ} \mathrm{C}$ heated pad, intubated, and ventilated using a mouse ventilator (Harvard Apparatus, Germany) with air (respiration frequency 120 strokes/min). Body temperature was maintained at about $37^{\circ} \mathrm{C}$ with the heating pad. Surface 12-lead ECG was recorded throughout the experiments on a Gould ACQ-7700 recorder (Gould Instrument Systems, Valley View, OH, USA). A left thoracotomy was performed, and the left anterior descending (LAD) coronary artery 2-3 $\mathrm{mm}$ from the tip of the left atrium was occluded with an Ethicon 8.0-silk suture (ETHICON, INC). Successful coronary occlusion was verified by the development of a pale color in the distal myocardium, which was observed using a Surgical Microscope system (Applied Fiberoptics, Southbride, Massachusetts), and by S-T segment elevation and QRS widening on the ECG. Blood flow was restored by releasing the ligature. Successful reperfusion was confirmed when the bright red color of the left ventricle (LV) and the ECG returned to normal. A 30-min coronary occlusion (ischemia) was used in the in vivo studies. Either a 40 -min or a 24 -h reperfusion period was used according to different protocols.

\section{In vivo EIPC, LIPC, and POC}

To simulate EIPC, 3 I/R cycles of 4 min each were applied immediately before a sustained 30-min ischemia followed by a 40 -min reperfusion, after which the chest was closed. Mice were allowed to recover for $24 \mathrm{~h}$ before their hearts were removed to measure infarct size. To simulate LIPC, 3 brief (4 min) I/ R cycles (IPC) were applied on d 1, and a sustained ischemia (30 $\mathrm{min}$ ) and reperfusion (40 $\mathrm{min}$ or $24 \mathrm{~h}$ ) injury was created on $\mathrm{d} 2$, while in the I/R controls, no IPC intervention was used on $\mathrm{d} 1$. To simulate POC, 6 brief cycles $(10 \mathrm{~s})$ of LAD reflow/reocclusion were applied during the first minute of reperfusion immediately following a 30-min LAD coronary artery occlusion, while the control group received no interventions during reperfusion.

\section{Ex vivo IPC and POC models (isolated Langendorff and working heart preparations)}

The aorta and left atrium were cannulated and connected to the HSE isolated heart perfusion system (model IH-1, Harvard Apparatus, Inc) immediately after removal from mice to allow measurements to be obtained in the working-heart mode (afterload=60 $\mathrm{mmHg}$, preload=10 $\mathrm{mmHg}$ ) as described previously $^{[26]}$. Left ventricular pressure (LVP), LV developed pressure (LVDP), and LV end-diastolic pressure (LVEDP) were measured with a Millar tip catheter $(1.4 / 0.8 \mathrm{~F}$ pressure transducer, Millar) inserted into the LV cavity through the aorta. Measurements of functional performance, including aortic pressure (AP), heart rate (HR), left ventricular pressure (LVP), LV developed pressure (LVDP), first derivative of maximum and minimum LVDP $( \pm \mathrm{d} p / \mathrm{d} t)$, and LV end-diastolic pressure 
(LVEDP) were recorded continuously during the experiment and analyzed offline by an HSE data acquisition system (HSE Haemodyn, Harvard Apparatus). Total global ischemia, which was produced by clamping both atrial inflow and aortic outflow, was used to induce sustained ischemia and IPC and POC interventions. Myocardial infarct size was determined using 2,3,5-triphenyltetrazolium chloride (TTC) staining as described previously ${ }^{[26]}$.

\section{Measurement of infarct size}

At the end of each protocol, the heart was stained with $0.1 \mathrm{~mL}$ $5 \%$ Phthalo Blue (Heucotech LTD, USA) and $1 \mathrm{~mL}$ of $1 \%$ TTC and then removed. The area at risk and the infarct size of the left ventricle were quantified by a blinded observer using the image processing and analysis (IPA) module of Simple PCI image analysis software (Compic, Inc, USA) ${ }^{[26]}$. The percent infarction was calculated for each slice and reported as the percent of infarct tissue divided by the total area at risk.

\section{Active caspase 3 assay}

Hearts from $\mathrm{CFTR}^{+/+}$or $\mathrm{CFTR}^{-/-}$mice were subjected to 45 min of ischemia and $180 \mathrm{~min}$ of reperfusion in the isolated Langendorff and working heart system to create I/R injury. Three brief 5-min cycles of I/R applied immediately before a sustained ischemic event were used for the IPC intervention. Control hearts were subjected to a $240-\mathrm{min}$ perfusion to evaluate baseline activated caspase 3 activity. At the end of the experiments, the hearts were snap frozen in liquid nitrogen and stored at $-80{ }^{\circ} \mathrm{C}$. The hearts were then pulverized and homogenized in RIPA buffer in the presence of a protease inhibitor cocktail (Sigma, Saint Louis, MO, USA, P8340) with a Kontes-Duall glass homogenizer. The homogenates were incubated on ice for $30 \mathrm{~min}$ and centrifuged in a microcentrifuge at maximal speed (about $14000 \mathrm{r} / \mathrm{min}$ ) for $10 \mathrm{~min}$ at $4{ }^{\circ} \mathrm{C}$. The supernatant (whole lysate) was collected, and protein concentrations were determined using the BCA protein assay. The supernatants were incubated with SDS loading buffer at $95{ }^{\circ} \mathrm{C}$ for $5 \mathrm{~min}$, separated by 12\% SDS-PAGE, and transferred to a nitrocellulose (NC) membrane for immunoblot analysis. Following SDS-PAGE, the NC membrane was blocked with Odyssey blocking buffer (Li-COR, Lincoln, NA, USA, 927-40000) for $45 \mathrm{~min}$ and incubated with primary rabbit polyclonal anti-active caspase 3 antibody $(1 \mu \mathrm{g} / \mathrm{mL}$, Abcam, ab2302) overnight at $4{ }^{\circ} \mathrm{C}$ with rocking. To detect active caspase 3 , the membrane was then incubated with Alexa Flour 680 goat anti-rabbit secondary antibody (dilution 1:50000, \#A21076, Invitrogen, Carlsbad, CA, USA) for $45 \mathrm{~min}$ at room temperature, and the membranes were washed and then scanned with the Odyssey infrared imaging system at $700 \mathrm{~nm}$ and processed with Odyssey software (V1.2, Li-COR). GAPDH was used as an internal control.

\section{TUNEL assay}

To identify apoptotic cells containing DNA fragments, tissue samples (serial $8 \mu \mathrm{m}$ cryosections) were immunohistochemically stained using terminal deoxynucleotidyl transferase
(TdT) and fluorescein conjugated nucleotides with the in situ cell death detection kit (Roche Applied Science, Indianapolis, IN) according to the manufacturer's instructions. Negative control sections were prepared without the TdT enzyme. Labeled nuclei were identified from the negative nuclei counterstained by propidium iodide (PI) (Vector Laboratories, Inc Burlingame, CA, USA) and counted after being photographed under a fluorescence microscope at $40 \times$ magnification. The percentage of TUNEL-positive nuclei (cell) was calculated as the number of TUNEL-labeled nuclei (green)/total nuclei (PIlabeled, red).

\section{Statistical analysis}

All group data are presented as the mean \pm SEM. ANOVA and Student's $t$ test were used to determine statistical significance. A 2-tailed probability value of $P<0.05$ was considered statistically significant.

\section{Results}

Functional role of CFTR in EIPC-mediated cardioprotection

Age-matched male $\mathrm{CFTR}^{+/+}, \mathrm{CFTR}^{+/-}$, and $\mathrm{CFTR}^{-/-}$mice were randomly divided into I/R (control) and EIPC groups following the experimental protocols depicted in Figure 1A. In the control group, mice were subjected to 24 min of open-chest exposure (sham) followed by a sustained 30-min occlusion and a 40-min reperfusion. In the EIPC group, 3 I/ R cycles of 4 min each were applied immediately before a sustained 30-min ischemia followed by a 40-min reperfusion, and then the chest was closed. The mice were allowed to recover for $24 \mathrm{~h}$ before the hearts were removed to measure infarct size. Representative images of Phthalo Blue and TTC stained LV sections from each group are shown in Figure 1B. As seen in Figure 1C, EIPC significantly reduced the size of the infarcts caused by 30-min sustained ischemia and 24-h reperfusion (expressed as a percentage of the risk region) in the $\mathrm{CFTR}^{+/+}$(from $40.4 \% \pm 5.3 \%$ to $10.4 \% \pm 2.0 \%, n=8, P<0.001)$ and $C F T R^{+/-}$mice (from $39.4 \% \pm 2.4 \%$ to $15.4 \% \pm 5.1 \%, n=6, P<0.001$ ). However, EIPC failed to protect the hearts of $\mathrm{CFTR}^{-/-}$mice $(46.9 \% \pm 6.2 \%$ in $\mathrm{I} / \mathrm{R}$ control vs $55.5 \% \pm 7.8 \%$ in EIPC, $n=6, P>0.5)$. These results suggest that $\mathrm{CFTR} \mathrm{Cl}^{-}$channels are involved in the cardioprotective effects of EIPC in vivo.

\section{Functional role of CFTR in LIPC-mediated cardioprotection}

To test whether CFTR is involved in LIPC cardioprotection in vivo, age-matched male $\mathrm{CFTR}^{+/+}, \mathrm{CFTR}^{+/-}$, and $\mathrm{CFTR}^{-/-}$ mice were randomly divided into four groups following the experimental protocols depicted in Figure 2A. In the LIPC group, 3 brief ( $4 \mathrm{~min}$ ) I/R cycles (IPC) were applied on $\mathrm{d} 1$, and a sustained ischemia (30 $\mathrm{min}$ ) and reperfusion (40 $\mathrm{min}$ or 24-h) injury was created on $\mathrm{d} 2$, while in the I/R controls, no IPC intervention was used on $\mathrm{d} 1$. The reason both a 40-min and a 24-h reperfusion were used in the LIPC protocols was to compare LIPC with EIPC and also to examine long term protection provided by LIPC. Similar to what was seen with EIPC, LIPC significantly reduced the size of the infarcts caused by sustained I/R injury in both $\mathrm{CFTR}^{+/+}$(from $44.9 \% \pm 5.1 \%$ 
A

\begin{tabular}{|c|c|c|c|c|}
\hline \multirow{3}{*}{$\begin{array}{l}\text { Group } 1 \\
\text { (I/R control) } \\
24-h \text { R }\end{array}$} & $24 \min$ & $30 \mathrm{~min}$ & $40 \mathrm{~min}$ & $24 \mathrm{~h}$ \\
\hline & Open chest & Ischemia & Reperfusion & Closed chest reperfusion \\
\hline & 444444 & $30 \mathrm{~min}$ & $40 \mathrm{~min}$ & $24 \mathrm{~h}$ \\
\hline $\begin{array}{l}\text { Group } 2 \\
\text { (IPC) }\end{array}$ & $|R| R \mid R$ & Ischemia & Reperfusion & Closed chest reperfusion \\
\hline
\end{tabular}

B
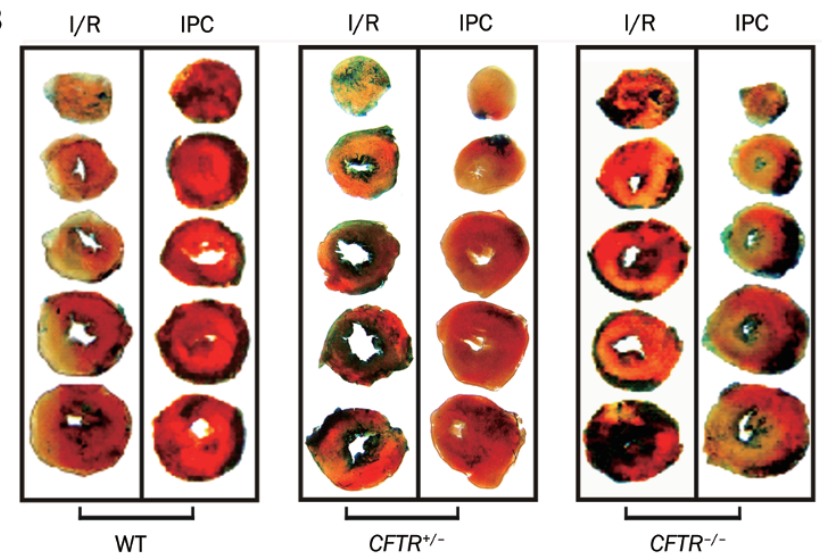

C

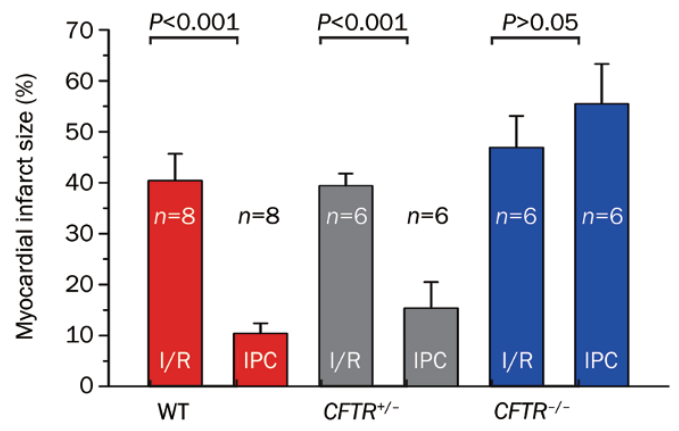

Figure 1. Effect of CFTR knockout on early preconditioning (EIPC). (A) Experimental protocols. Protocol for each group is applied to $\mathrm{CFTR}^{-/-}$ mice and age-matched $\mathrm{CFTR}^{+/+}$(WT) and $\mathrm{CFTR}^{+/-}$littermates. (B) Representative tissue staining of transverse slices from age-matched WT, $\mathrm{CFTR}^{+/-}$, or $\mathrm{CFTR}^{-/-}$mice. (C) Mean infarct size measured from agematched WT, CFTR ${ }^{+/-}$, or $\mathrm{CFTR}^{-/-}$mouse heart in group 1 (I/R) and 2 (IPC). to $20.6 \% \pm 2.6 \%, n=7, P<0.001$ in the groups with 40 -min reperfusion and from $39.6 \% \pm 4.1 \%$ to $18.3 \% \pm 1.8 \%, n=6, P<0.001$ in the groups with 24-h reperfusion) and $\mathrm{CFTR}^{+/-}$mice (from $39.9 \% \pm 4.1 \%$ to $19.4 \% \pm 1.7 \%, n=6, P<0.001$ in the groups with 40 -min reperfusion, and from $40.2 \% \pm 3.2 \%$ to $21.6 \% \pm 2.0 \%$, $n=5, P<0.001$ in the groups subjected to 24 -h reperfusion). However, LIPC failed to provide protection against I/ $R$ injury in hearts from $\mathrm{CFTR}^{-/-}$mice $(42.6 \% \pm 4.1 \%$ in control vs $40.8 \% \pm 5.3 \%$ in LIPC with 40 -min reperfusion, $n=7, P>0.05$, and $36.8 \% \pm 3.2 \%$ in control vs $39.8 \% \pm 4.7 \%$ in LIPC with 24 -h reperfusion, $n=5, P>0.05$ ), as shown in Figures $2 \mathrm{~B}$ and $2 \mathrm{C}$. These results strongly indicate that CFTR may play a very important role in LIPC-mediated cardioprotection in the mouse heart.

\section{Functional role of CFTR in POC-mediated cardioprotection}

To examine whether CFTR $\mathrm{Cl}^{-}$channels play a role in POC, we first established an ex vivo model of POC. Isolated Langendorff (retrograde) and working-heart (antegrade) perfusion preparations ${ }^{[26]}$ from $C F T R^{-/-}$and $C F T R^{+/+}$mice were subjected to the experimental protocols shown in Figure 3A. Functional and histological changes to the hearts during I/R and POC were studied. A 45-min period of ischemia was applied as the index ischemia. Six cycles of 10-s ischemia/reperfusion initiated in the first minute of reperfusion following the index ischemia were used as the POC intervention. I/R groups received no interventions during reperfusion. As shown in Table $1, I / R$ injury caused a significant decrease in heart function as evaluated by HR, LVDP, and $\pm \mathrm{d} p / \mathrm{d} t$ in both CFTR ${ }^{+/+}$and CFTR ${ }^{-/-}$ mice; however, in hearts subjected to POC, post-ischemic cardiac function was restored to levels close to the baseline seen before the ischemic event in $\mathrm{CFTR}^{+/+}$but not $\mathrm{CFTR}^{-/-}$mice.

The infarct size was also measured to assess myocardial tissue injury and viability, and representative images of stained $\mathrm{LV}$ sections from each group are shown in Figure 3B. The size of infarcts caused by $45-\mathrm{min}$ ischemia was significantly reduced from $37.5 \% \pm 3.4 \%$ to $17 \% \pm 2.0 \%(P<0.005, n=4)$ by POC in the hearts of $\mathrm{CFTR}^{+/+}$mice but not $\mathrm{CFTR}^{-/-}$mice (control, $40.4 \% \pm 4.1 \%$ vs POC $45 \% \pm 7.7 \%, P>0.1, n=5$ ). These results strongly suggest that targeted inactivation of the CFTR gene in

Table 1. Effects of CFTR gene knockout on POC-induced changes in hemodynamics of the isolated perfused mouse heart. ${ }^{b} P<0.05,{ }^{c} P<0.01,40-m i n ~ R$ vs baseline. Data are represented as mean \pm SEM.

\begin{tabular}{|c|c|c|c|c|c|c|c|c|}
\hline & \multicolumn{4}{|c|}{ CFTR $^{+/+}$} & \multicolumn{4}{|c|}{ CFTR $^{-/-}$} \\
\hline & Baseline & 40-min R & Baseline & 40-min R & Baseline & 40-min R & Baseline & 40-min R \\
\hline Heart rate $(\mathrm{bpm})$ & $387 \pm 29$ & $312 \pm 14^{b}$ & $397 \pm 10$ & $379 \pm 15$ & $378 \pm 20$ & $295 \pm 5^{b}$ & $419 \pm 18$ & $303 \pm 6$ \\
\hline LVDP (mmHg) & $100.5 \pm 2.2$ & $61.6 \pm 5.6^{b}$ & $103.9 \pm 4.0$ & $89.7 \pm 49$ & $113.9 \pm 8.4$ & $66.1 \pm 6.9^{b}$ & $118.7 \pm 11.0$ & $69.2 \pm 2.3^{b}$ \\
\hline$+\mathrm{dp} / \mathrm{d} t(\mathrm{mmHg} / \mathrm{s})$ & $7313 \pm 290$ & $2874 \pm 125^{c}$ & $8215 \pm 298$ & $6451 \pm 476^{b}$ & $8689 \pm 101$ & $3088 \pm 234^{c}$ & $7914 \pm 1042$ & $3706 \pm 494^{c}$ \\
\hline
\end{tabular}

I/R: ischemia/reperfusion; LVDP: left ventricular developed pressure; $+\mathrm{d} p / \mathrm{dt}$ : maximum rate of change in LVDP; -dp/dt: minimum rate of change in LVDP. Hemodynamic parameters at baseline were measured at the end of the $10 \mathrm{~min}$ of working heart perfusion before ischemia/reperfusion protocol. Results measured at the end of 40 min of reperfusion (40-min R) after $45 \mathrm{~min}$ of global ischemia without postconditioning (I/R) or with postconditioning (POC) were compared with those measured at baseline. 


\begin{tabular}{|c|c|c|c|c|}
\hline \multirow{3}{*}{$\begin{array}{l}\text { Group } 1 \\
\text { (I/R control 40-min R) }\end{array}$} & Day 1 & Day 2 & & \\
\hline & $24 \mathrm{~min}$ & $30 \mathrm{~min}$ & $40 \mathrm{~min}$ & \\
\hline & Open chest & Ischemia & Reperfusion & \\
\hline \multirow{2}{*}{$\begin{array}{l}\text { Group } 2 \\
\text { (LIPC 40-min R) }\end{array}$} & $444444 \mathrm{~min}$ & $30 \mathrm{~min}$ & $40 \mathrm{~min}$ & \\
\hline & & Ischemia & Reperfusion & \\
\hline \multirow{2}{*}{$\begin{array}{l}\text { Group } 3 \\
\text { (1/R control 24-h R) }\end{array}$} & $24 \mathrm{~min}$ & $30 \mathrm{~min}$ & $40 \mathrm{~min}$ & $24 \mathrm{~h}$ \\
\hline & Open chest & Ischemia & Reperfusion & Closed chest reperfusion \\
\hline \multirow{2}{*}{$\begin{array}{l}\text { Group } 4 \\
\text { (LIPC 24-h R) }\end{array}$} & $444444 \mathrm{~min}$ & $30 \mathrm{~min}$ & $40 \mathrm{~min}$ & $24 \mathrm{~h}$ \\
\hline & $|R| R \mid R$ & Ischemia & Reperfusion & Closed chest reperfusion \\
\hline
\end{tabular}

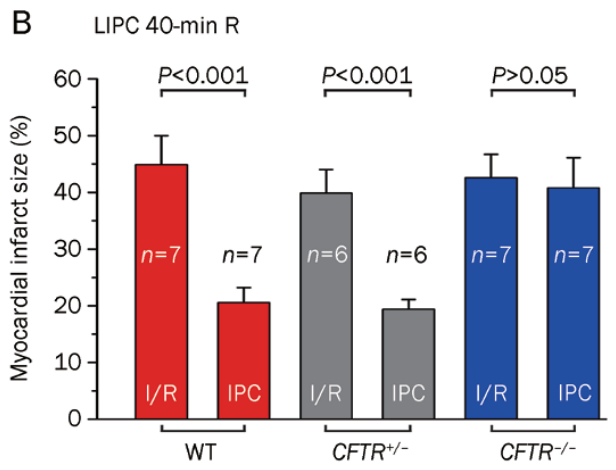

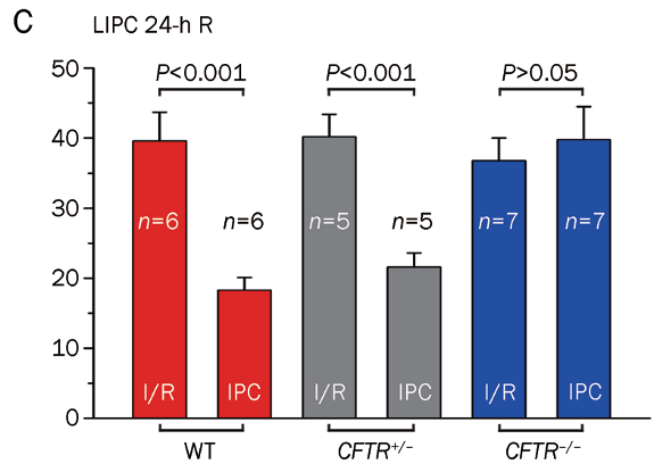

Figure 2. Effect of CFTR knockout on late (second window) preconditioning (LIPC). (A) Experimental protocols. Protocol for each group is applied to $\mathrm{CFTR}^{-/-}$mice and agematched WT and $\mathrm{CFTR}^{+/-}$littermates. (B) Mean infarct size in Group 1 (I/R) \& 2 (IPC) with 40-min reperfusion. (C) Mean infarct size in Group 3 (I/R) \& 4 (IPC) with $24 \mathrm{hr}$ reperfusion.

\begin{tabular}{|c|c|c|c|c|c|}
\hline A & $10 \mathrm{~min}$ & $30 \mathrm{~min}$ & $45 \mathrm{~min}$ & $15 \mathrm{~min}$ & $25 \mathrm{~min}$ \\
\hline $1 / R$ & W & $P$ & Ischemia & $\mathrm{R}$ & W \\
\hline POC & W & $\mathrm{P}$ & Ischemia & $\mathrm{R}$ & W \\
\hline
\end{tabular}

B

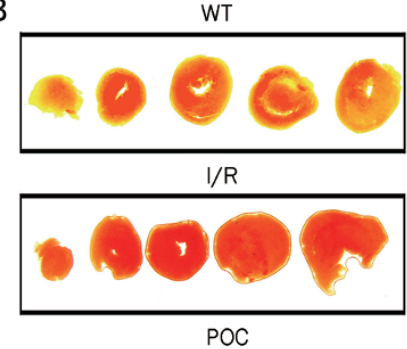

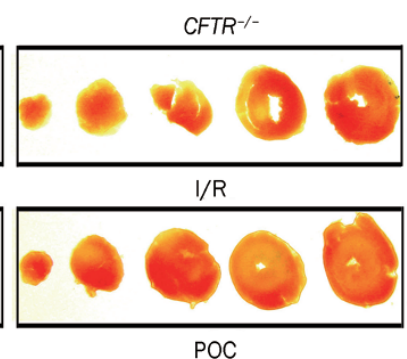

C

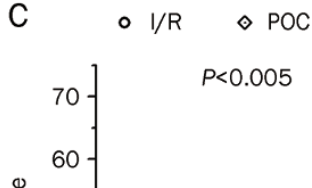

$\triangle \mathrm{I} / \mathrm{R} \quad \nabla \mathrm{POC}$

$P>0.1$

$\nabla$

$\nabla$
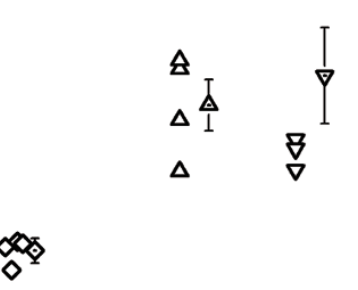

WT

CFTR $^{-/-}$

Figure 3. Effects of CFTR knockout on postconditioning (POC) in isolated hearts. (A) Experimental protocols. Protocol for each group is applied to $\mathrm{CFTR}^{-/-}$mice and age-matched WT littermates. W: working, P: perfusion, R: reperfusion. (B) Representative staining of ventricle transverse slices after ischemia/reperfusion (I/R) or postconditioning (POC). (C) Individual infarct size measured from each age- and gender-matched WT and CFTR ${ }^{-/-}$mouse hearts after control or POC, mean value with error bar (mean \pm SEM) were also shown for each group.

the mouse abolishes the cardioprotective effect of POC against sustained I/ R in isolated hearts.

A "gold standard" for confirmation of the potential role of CFTR $\mathrm{Cl}^{-}$channels in POC protection is to test whether POC also protects the heart from in vivo I/R injury. Therefore, an in vivo model of POC was established in $\mathrm{CFTR}^{-/-}$mice and their $\mathrm{CFTR}^{+/+}$littermates to test the effects of targeted inactivation of the CFTR gene on in vivo POC protection in mice.

Open-heart surgery was performed on male CFTR ${ }^{-/-}$mice
(8-12 week-old) and age-matched $\mathrm{CFTR}^{+/+}$and CFTR ${ }^{+/-}$littermates, and coronary artery occlusion and POC protocols were performed (Figure 4A). Immediately following a 30-min LAD coronary artery occlusion, which was applied as the index ischemia to induce about $40 \%$ infarct size in the hearts of mice in the control group, 6 brief cycles (10 s) of LAD reflow/reocclusion were applied in the first minute of reperfusion, while the control group received no interventions during reperfusion. At the end of each experimental protocol, the hearts 
A

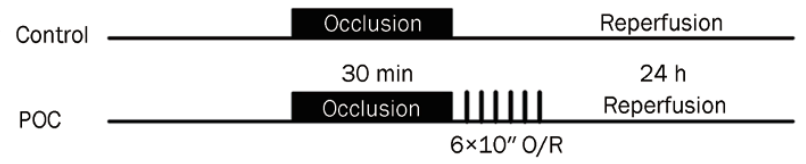

B

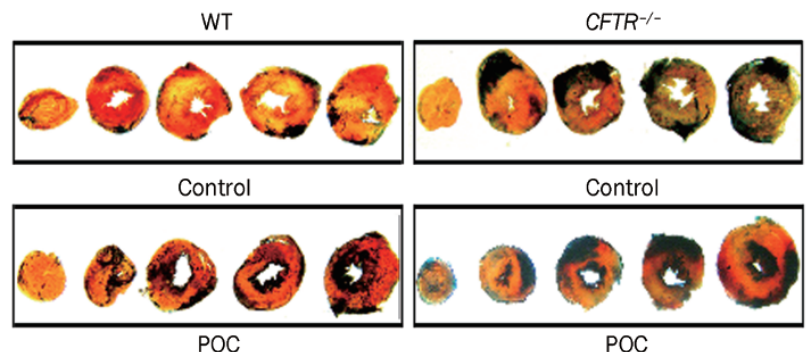

C

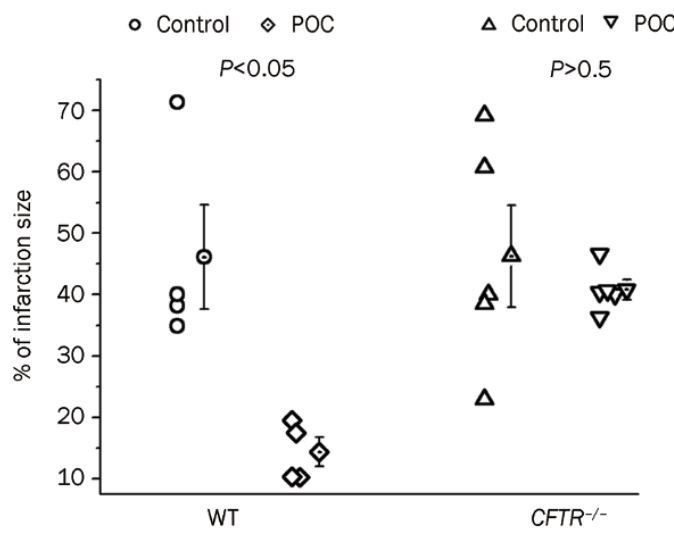

Figure 4. Effects of CFTR knockout on postconditioning (POC) in vivo. (A) Experimental protocols. Protocol for each group is applied to CFTR ${ }^{-/-}$mice and age-matched WT littermates. O/R: occlusion/reperfusion. (B) Representative staining of ventricle transverse slices after ischemia/reperfusion (I/R) or postconditioning (POC). (C) Individual infarct size measured from each age- and gender-matched WT and CFTR ${ }^{-/-}$mouse hearts after control or POC, mean value with error bar (mean \pm SEM) were also shown for each group.

were stained by TTC and Phthalo Blue (Figure 4B) and the infarct size (\% of the region at risk) was calculated. As seen in Figure 4C, a 30-min ischemia/24-h reperfusion caused an infarct size of $46.1 \% \pm 8.5 \%(n=4)$ in $C F T R^{+/+}$mice and an infarct size of $46.3 \% \pm 8.3 \%(n=5)$ in $C_{F T R^{-/-}}$mice. POC significantly reduced the infarct size within the risk zone to $14.4 \% \pm 2.4 \%$ $(n=4, P<0.05)$ in the $C F T R^{+/+}$mice but not in the CFTR $R^{-/-}$mice $(40.8 \% \pm 1.2 \%, n=5, P>0.5)$. These results further confirm an important role of CFTR in POC-mediated cardioprotection against I/R injury in mouse hearts.

\section{Effect of targeted inactivation of the CFTR gene on apoptosis}

It has been demonstrated previously that apoptosis and necrosis are the major cell death pathways involved in I/R injury and myocardial infarction and that both IPC and POC can reduce I/R-induced apoptosis ${ }^{[1,2,32,33]}$. To test whether activation of $\mathrm{CFTR} \mathrm{Cl}^{-}$channels is important in IPC-mediated inhibition of apoptosis, isolated Langendorff and working heart preparations from ex vivo IPC models from age-matched male $\mathrm{CFTR}^{+/+}$and $\mathrm{CFTR}^{-/-}$mice were examined. As shown in Figure 5, post-ischemic functional performance, as estimated by LVDP,$+\mathrm{d} p / \mathrm{d} t$, and $-\mathrm{d} p / \mathrm{d} t$, was significantly improved by IPC in $\mathrm{CFTR}^{+/+}$mouse hearts compared to non-preconditioned $\mathrm{CFTR}^{+/+}$mouse hearts but not in $\mathrm{CFTR}^{-/-}$mouse hearts (Figure 5B-5D). A separate group of control hearts was subjected to normal perfusions without $I / R$ to investigate the amount of apoptosis that develops during $\mathrm{I} / \mathrm{R}$ using the isolated heart perfusion system. Our results showed that a 240-min perfusion resulted in little caspase 3 activation (control) but that sustained I/ R caused a significant increase in caspase 3 activation in both $C F T R^{+/+}$and CFTR ${ }^{-/-}$mouse hearts. I/R induced caspase 3 activation, however, was significantly reduced by IPC in hearts of $C F T R^{+/+}$mice to a level similar to that of $\mathrm{CFTR}^{+/+}$control mice. In hearts of $\mathrm{CFTR}^{-/-}$mice, the level of active caspase 3 was not reduced by IPC, indicating loss of IPC-induced inhibition of apoptosis in these hearts (Figure 5A and $5 \mathrm{~B})$.

To confirm our observations on the effects of knocking out CFTR on apoptosis of cardiac myocytes, TUNEL assays were performed to detect apoptotic cells under I/R and IPC conditions. Figure $5 \mathrm{C}$ shows a representative image of TUNEL assays in mouse heart sections. In these studies, the reperfusion time was increased to $>360 \mathrm{~min}$ to allow DNA damage to develop. In control hearts not subjected to global I/R, $420 \mathrm{~min}$ of perfusion led to the appearance of some TUNEL-positive (TN-P) nuclei in the epicardium, but no TN-P nuclei were detected in the deeper layers of the myocardium (data not show). I/ $\mathrm{R}$ resulted in the appearance of $26.1 \% \pm 2.15 \%$ and $29.28 \% \pm 4.98 \%$ TN-P nuclei in hearts of $C_{F T R}{ }^{+/+}$and $C_{F T R} /-$ mice, respectively. IPC significantly reduced TN-P nuclei in hearts of $C F T R^{+/+}$mice $(3.77 \pm 0.28, P<0.001)$ but not hearts of $C_{F T R^{-/-}}$mice $(24.79 \% \pm 3.17 \%, P>0.1)$ (Figure 5D). These results suggest that CFTR is very important for IPC-mediated inhibition of apoptosis in the heart.

\section{Discussion}

Although our previous study in isolated heart preparations suggested a potential role of CFTR in acute IPC, it is not clear what the exact function of CFTR is in in vivo EIPC and LIPC or whether CFTR is involved in $\mathrm{POC}^{[26-28]}$. In this study, therefore, we investigated the relative role of CFTR $\mathrm{Cl}^{-}$channels in in vivo EIPC and LIPC in the mouse heart. Our results demonstrate that CFTR $\mathrm{Cl}^{-}$channels are important for both EIPCand LIPC-mediated cardioprotection. In addition, our results provide strong evidence for a novel and critical role for CFTR $\mathrm{Cl}^{-}$channels in POC-mediated cardioprotection. Furthermore, we found that CFTR may exert its cardioprotective effects through inhibition of apoptosis.

Functional role of $\mathrm{Cl}^{-}$channels in IPC-medicated cardioprotection For historical reasons, the potential role of $\mathrm{Cl}^{-}$channels in cardiac physiology has been ignored ${ }^{[27,28]}$. The first evidence for 
A

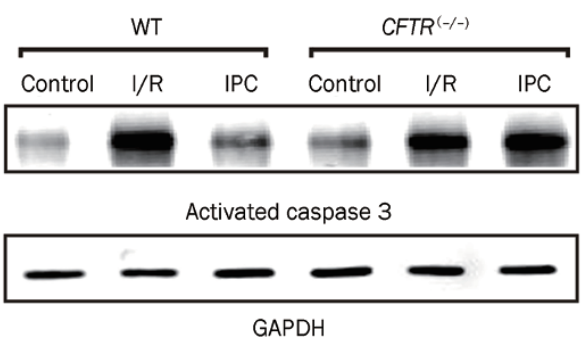

C
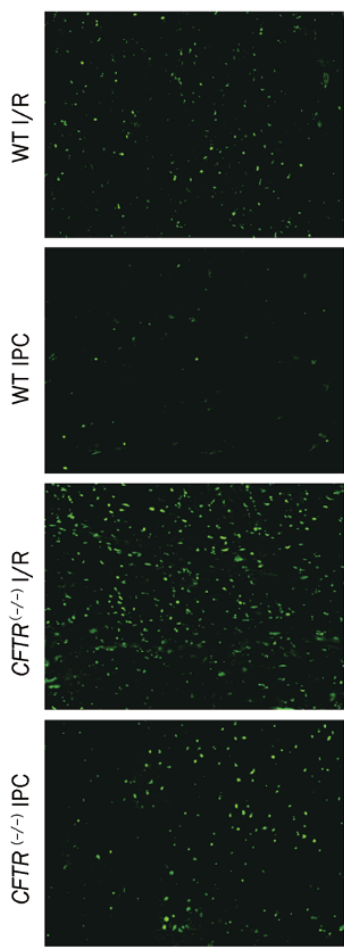

TUNEL+PI
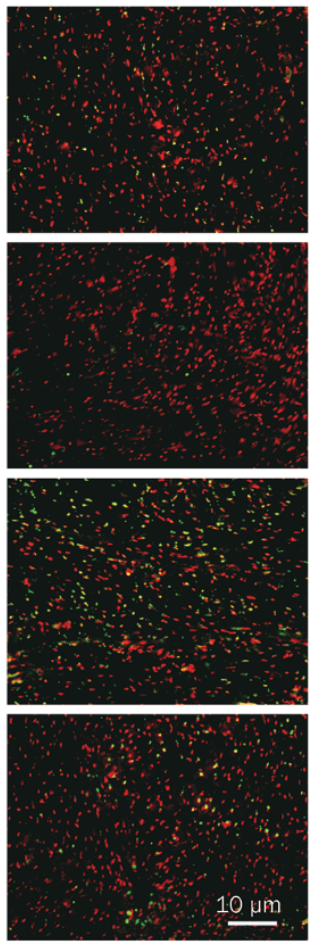

B

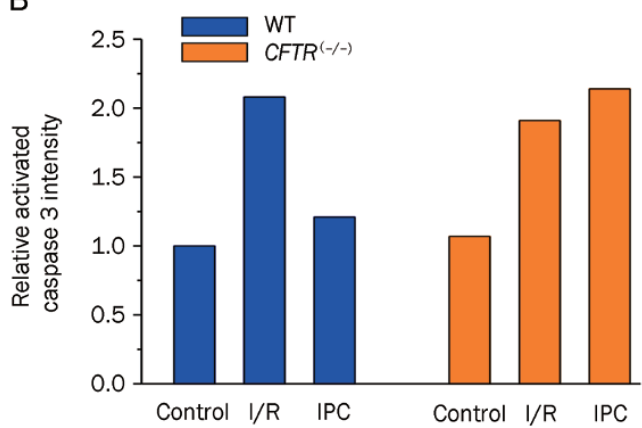

D

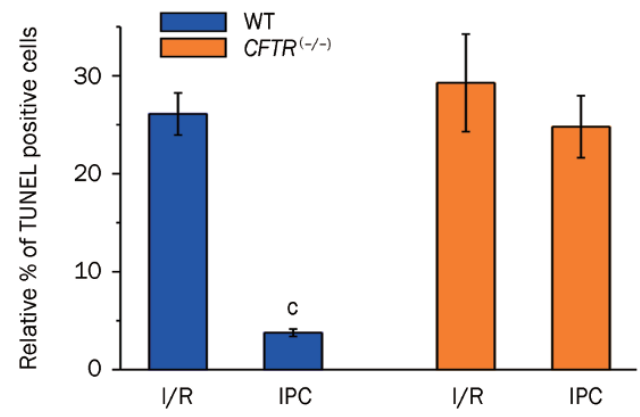

Figure 5. Effects of targeted inactivation of CFTR gene on apoptosis during I/R or IPC. (A) Western blots (WB) analysis of activated caspase 3 in an isolated perfusion heart model for either WT or $\mathrm{CFTR}^{-/-}$mice exposed to reperfusion alone (control), ischemia/reperfusion (I/R) or ischemic preconditioning (IPC) protocols. After control ( $5 \mathrm{~h}$ perfusion), I/R (45 min ischemia/3 h reperfusion) or IPC ( 3 cycles of $5 \mathrm{~min}$ I/R right before the $45 \mathrm{~min}$ ischemia/3 h reperfusion) treatments, hearts lysates from each group were obtained and subjected to WB analysis for activated caspase 3. GAPDH was immunoblotted as a loading control. (B) Relative active caspase-3 density after normalized to GAPDH. (C) Representative images of heart longitudinal sections of TUNEL staining for each group of treatments: I/R (45 min ischemia/ $6 \mathrm{~h}$ reperfusion) or IPC ( 3 cycles of 5 min I/R right before the 45 min ischemia/ $6 \mathrm{~h}$ reperfusion). Green: TUNEL stained nuclei; red, propidium iodide (PI) stained nuclei. (D) Relative percentage of TUNEL positive (TP) cells calculated as $100 \%$ * (count of TP/count of PI), data presented as mean \pm SEM (error bar). $n=6 .{ }^{\circ} P=0.0027$.

the potential involvement of $\mathrm{Cl}^{-}$channels in IPC came from a study by Diaz et al, which demonstrated that the $\mathrm{Cl}^{-}$channel blockers 5-nitro-2-(3-phenylpropyl-amino) benzoic acid (NPPB) and indanyloxyacetic acid 94 (IAA-94) not only block hypo-osmotic cell swelling induced by $\mathrm{Cl}^{-}$current $\left(I_{\mathrm{Cl} \text {, swell }}\right)$ but also prevent IPC- and hypo-osmotic stress-mediated protection of isolated rabbit hearts ${ }^{[13]}$. Subsequent studies from the same group provided further evidence supporting the notion that $I_{\mathrm{Cl} \text {, swell }}$ may be an important end-effector in $\mathrm{IPC}^{[34,35]}$, and it is believed that enhanced cell volume regulation may be a key mechanism for IPC protection ${ }^{[12]}$. These observations by Diaz et al were, however, seriously questioned by Heusch et al ${ }^{[36,37]}$.
In an attempt to confirm the effects of the same $\mathrm{Cl}^{-}$channel blockers on both $\mathrm{Cl}^{-}$channel activity in isolated ventricular myocytes and cardioprotection by IPC in isolated perfused rabbit heart, Heusch et al found that the channel-blocking concentrations of both NPPB and IAA-94 were toxic in isolated perfused rabbit hearts, as evidenced by cessation of cardiac contraction and massive infarction. Thus, neither agent could be used to test the role of $\mathrm{Cl}^{-}$channels on the anti-infarct effect of IPC. The doses used in the report by Diaz et $a l^{[13]}$ did not affect coronary flow, heart rate, or developed pressure and also failed to prevent infarct size reduction by $\mathrm{IPC}^{[36]}$. Similar results were obtained with another VSOACs blocker, 4,4'- 
diisothiocyanostilbene-2, $2^{\prime}$-disulfonic acid (DIDS) ${ }^{[36]}$. Therefore, whether cardiac $\mathrm{Cl}^{-}$channels play a role in IPC remains controversial.

The difficulty in resolving these controversies stems from the fact that multiple types of $\mathrm{Cl}^{-}$channels (CFTR, $I_{\mathrm{Cl} \text {, swell }}$ etc) are concomitantly expressed in the same cardiac cell ${ }^{[27,28]}$, and the $\mathrm{Cl}^{-}$channel blockers used in these studies lack specificity towards any particular subgroup of $\mathrm{Cl}^{-}$channels in the heart ${ }^{[13,35,36]}$. Therefore, the use of a gene targeting technique to specifically inactivate $\mathrm{Cl}^{-}$channel (eg, CFTR) gene expression in the mouse provides a unique and powerful approach to directly address the question of whether $\mathrm{Cl}^{-}$channels play a role in the early and late phases of IPC.

\section{Relationship between CFTR and sarc- $K_{\text {ATP }}$ channels}

CFTR belongs to the ABC transport superfamily ${ }^{[38]}$ and shares similar structural features, including transmembrane and nucleotide binding domains, with SUR, a subunit of functional sarc- $\mathrm{K}_{\mathrm{ATP}}$ channels ${ }^{[39]}$. However, CFTR is the only member of the $\mathrm{ABC}$ family that encodes a protein with a transport structure and $\mathrm{Cl}^{-}$channel function ${ }^{[38]}$. CFTR is unique in forming an anion channel gated by PKA and PKC phosphorylation and intracellular $\mathrm{ATP}^{[29,30]}$. Interestingly, sulfonylureas such as glibenclamide, which have long been used as specific blockers of sarc- $\mathrm{K}_{\mathrm{ATP}}$ channels in IPC studies ${ }^{[8,9]}$, can also block CFTR $\mathrm{Cl}^{-}$channels ${ }^{[40,41]}$. However, a potential role for $\mathrm{CFTR} \mathrm{Cl}^{-}$ channels as endogenous protective factors in IPC and POC has been ignored. In this study, we provide the first compelling experimental evidence for a novel and critical functional role of CFTR channels in IPC- and POC-mediated cardioprotection. Therefore, CFTR may represent a novel target for cardioprotection against I/R injury.

\section{Mechanisms of activation of CFTR in IPC- and POC-mediated cardioprotection against $\mathrm{I} / \mathrm{R}$ injury}

CFTR $\mathrm{Cl}^{-}$channels are expressed in many species ranging from mice to humans ${ }^{[29]}$. It is well established that cardiac CFTR channels can be activated by PKA and PKC through a vast array of signaling pathways such as activation of $\beta$-adrenergic receptors ${ }^{[2]]}$ and purinergic receptors ${ }^{[42]}$. It is thus conceivable that cardiac CFTR channels can be activated by signaling mechanisms invoked during IPC and POC, including $\mathrm{PKC} \varepsilon$ activation via G-protein (possibly Gq and/or Gi)coupled receptors ${ }^{[17,18]}$.

Apoptosis and necrosis are the major cell death mechanisms involved in ischemia- and reperfusion-induced myocardial injury and infarction ${ }^{[1,2]}$. Considerable evidence has demonstrated that activation of CFTR channels may be an important modulator of apoptotic mechanism in non-cardiac cells $^{[43-45]}$. For example, glibenclamide, an inhibitor of CFTR $\mathrm{Cl}^{-}$channels ${ }^{[40,41]}$ that has been mistaken as a specific blocker of sarc- $\mathrm{K}_{\text {ATP }}$ channels ${ }^{[8,9]}$, induces apoptosis in a dose- and time-dependent manner in HepG2 human hepatoblastoma cells $^{[43]}$. In this study, we found that targeted inactivation of CFTR abolished the protective effects of IPC on I/R-induced apoptosis, suggesting that CFTR channels may be involved in IPC- and POC-mediated cardioprotection through inhibition of apoptosis. It has been suggested that the anti-apoptotic effect of CFTR may be a result of strengthened cell volume homeostasis during cell proliferation and apoptosis ${ }^{[46]}$. Other mechanisms behind CFTR-mediated effects on apoptosis may involve the role of CFTR in the regulation of intracellular reactive oxygen species (ROS) and glutathione content (GSH/ GSSG) ${ }^{[47]}$. It should be pointed out, however, that in several other cell types, activation of CFTR has been reported to actually enhance apoptosis ${ }^{[47-49]}$. The reason for the multifaceted role of CFTR in apoptosis is not currently known ${ }^{[50]}$. However, Yalcin et al recently found that the majority of apoptotic cells in CF patients are alveolar epithelial cells, and apoptotic cells are not detected in other locations where CFTR expression is much more prominent than alveolar cells. They postulated, therefore, that increased apoptosis in the alveolar epithelium is related to the presence of chronic infections rather than CFTR dysfunction $^{[51]}$.

In addition, activation of $\mathrm{CFTR} \mathrm{Cl}^{-}$channels may protect the heart against arrhythmogenesis by preventing excessive prolongation of action potential duration (APD) and protecting the heart against the development of early after depolarizations (EAD) and triggered activity caused by activation of $\mathrm{Ca}^{2+}$ channels in the presence of $\beta$-adrenergic stimulation ${ }^{[28,29]}$. It has been demonstrated that cardiac CFTR plays a role in early action potential shortening during hypoxia and ischemia ${ }^{[52]}$. Activation of CFTR also decreases resting membrane potential and action potential duration, thereby limiting intracellular $\mathrm{Ca}^{2+}$ overload and cell damage ${ }^{[29]}$. These beneficial effects of the activation of cardiac CFTR may serve as mechanisms behind the cardioprotection of CFTR against I/R injury during IPC or POC.

Numerous previous studies have demonstrated that CFTR is not only a $\mathrm{Cl}^{-}$channel but also a transporter for many other molecules such as sphingosine-1-phosphate ${ }^{[53]}$, an important lipid messenger involved in IPC ${ }^{[54]}$. CFTR may interact with many proteins that either directly or indirectly impact the function of other ion channels and transporters, such as epithelial $\mathrm{Na}^{+}$channels $(\mathrm{ENaC})$ and $\mathrm{Ca}^{2+}$ - and volume-activated $\mathrm{Cl}^{-}$channels ${ }^{[55]}$. Evidence is emerging that CFTR assembles into large, dynamic macromolecular complexes that contain signaling molecules, kinases, transport proteins, PDZ-domaincontaining proteins, myosin motors, and Rab GTPases ${ }^{[56]}$. Therefore, CFTR may be involved in the regulation of a variety of cellular functions. The integrated versatile function and complex regulation of CFTR channels may be orchestrated by a number of proteins in the CFTR interactome ${ }^{[57]}$. It is thus very important to further study the underlying molecular mechanisms behind CFTR-mediated cardioprotection and the interplay between CFTR and other cardioprotective factors such as sarc- $\mathrm{K}_{\mathrm{ATP}}$, mito- $\mathrm{K}_{\mathrm{ATP}}$, and $\mathrm{mPTP}$. Such studies may shed new light on the functional role of $\mathrm{CFTR} \mathrm{Cl}^{-}$channels in the heart and increase our understanding of the complicated mechanisms behind endogenous cardioprotection. 


\section{Acknowledgements}

We are grateful to Dr William HATTON and Dr Hong-lin TIAN for their excellent technical assistance. This study was supported by the National Center for Research Resources P-20 RR-15581 (Dayue Darrel DUAN); National Heart, Lung, and Blood Institute Grants HL106256 and HL63914 (Dayue Darrel DUAN), HL60051 (John A AUCHAMPACH), HL 077707 (John A AUCHAMPACH), and HL 08311 (Garrett J GROSS); American Diabetes Association Innovation Award \#07-8-IN-08 (Dayue Darrel DUAN); and the National Basic Research Program of China Grant 2009CB521903 (Dayue Darrel DUAN).

\section{References}

1 Lopez-Neblina F, Toledo AH, Toledo-Pereyra LH. Molecular biology of apoptosis in ischemia and reperfusion. J Invest Surg 2005; 18 : 335-50.

2 Zhao ZQ, Vinten-Johansen J. Myocardial apoptosis and ischemic preconditioning. Cardiovasc Res 2002; 55: 438-55.

3 Murry CE, Jennings RB, Reimer KA. Preconditioning with ischemia: a delay of lethal cell injury in ischemic myocardium. Circulation 1986; 74: 1124-36.

4 Guo Y, Wu WJ, Qiu Y, Tang XL, Yang Z, Bolli R. Demonstration of an early and a late phase of ischemic preconditioning in mice. Am J Physiol 1998; 275: H1375-87.

5 Ludman AJ, Yellon DM, Hausenloy DJ. Cardiac preconditioning for ischaemia: lost in translation. Dis Model Mech 2010; 3: 35-8.

6 Ovize M, Baxter GF, Di LF, Ferdinandy P, Garcia-Dorado D, Hausenloy DJ, et al. Postconditioning and protection from reperfusion injury: where do we stand? Position paper from the Working Group of Cellular Biology of the Heart of the European Society of Cardiology. Cardiovasc Res 2010; 87: 406-23.

7 Downey JM, Davis AM, Cohen MV. Signaling pathways in ischemic preconditioning. Heart Fail Rev 2007; 12: 181-8.

8 Gross GJ, Peart JN. K KATP channels and myocardial preconditioning: an update. Am J Physiol Heart Circ Physiol 2003; 285: H921-30.

9 Gross GJ. Selective ATP-sensitive potassium channel openers: fact or fiction. J Mol Cell Cardiol 2003; 35: 1005-7.

10 Hausenloy DJ, Ong SB, Yellon DM. The mitochondrial permeability transition pore as a target for preconditioning and postconditioning. Basic Res Cardiol 2009; 104: 189-202

11 Xiao XH, Allen DG. Activity of the $\mathrm{Na}^{+} / \mathrm{H}^{+}$exchanger is critical to reperfusion damage and preconditioning in the isolated rat heart. Cardiovasc Res 2000; 48: 244-53.

12 Diaz RJ, Armstrong SC, Batthish M, Backx PH, Ganote CE, Wilson GJ. Enhanced cell volume regulation: a key protective mechanism of ischemic preconditioning in rabbit ventricular myocytes. J Mol Cell Cardiol 2003; 35: 45-58.

13 Diaz RJ, Losito VA, Mao GD, Ford MK, Backx PH, Wilson GJ. Chloride channel inhibition blocks the protection of ischemic preconditioning and hypo-osmotic stress in rabbit ventricular myocardium. Circ Res 1999; 84: 763-75.

14 Downey JM, Cohen MV. Why do we still not have cardioprotective drugs? Circ J 2009; 73: 1171-7.

15 Mclntosh VJ, Lasley RD. Adenosine receptor-mediated cardioprotection: are all 4 subtypes required or redundant? J Cardiovasc Pharmacol Ther 2011 doi:10.1177/1074248410396877.

16 Zhao ZQ, Corvera JS, Halkos ME, Kerendi F, Wang NP, Guyton RA, et al. Inhibition of myocardial injury by ischemic postconditioning during reperfusion: comparison with ischemic preconditioning. Am J Physiol Heart Circ Physiol 2003; 285: H579-88.
17 Zhao ZQ, Vinten-Johansen J. Postconditioning: reduction of reperfusion-induced injury. Cardiovasc Res 2006; 70: 200-11.

18 Gross GJ, Auchampach JA. Reperfusion injury: does it exist? J Mol Cell Cardiol 2007; 42: 12-8.

19 Philipp S, Yang XM, Cui L, Davis AM, Downey JM, Cohen MV. Postconditioning protects rabbit hearts through a protein kinase $\mathrm{C}$-adenosine A2b receptor cascade. Cardiovasc Res 2006; 70: 308-14.

20 Heusch G, Buchert A, Feldhaus S, Schulz R. No loss of cardioprotection by postconditioning in connexin 43-deficient mice. Basic Res Cardiol 2006; 101: 354-6.

21 Skyschally A, van Caster P, Boengler K, Gres P, Musiolik J, Schilawa $D$, et al. Ischemic postconditioning in pigs: no causal role for RISK activation. Circ Res 2009; 104: 15-8.

22 Peart JN, Headrick JP. Clinical cardioprotection and the value of conditioning responses. Am J Physiol Heart Circ Physiol 2009; 296: H1705-20.

23 Heusch G. Postconditioning: old wine in a new bottle? J Am Coll Cardiol 2004; 44: 1111-2.

24 Burley DS, Baxter GF. Pharmacological targets revealed by myocardial postconditioning. Curr Opin Pharmacol 2009; 9: 177-88.

25 Granfeldt A, Lefer DJ, Vinten-Johansen J. Protective ischaemia in patients: preconditioning and postconditioning. Cardiovasc Res 2009; 83: 234-46.

26 Chen H, Liu LL, Ye LL, McGuckin C, Tamowski S, Scowen P, et al. Targeted inactivation of cystic fibrosis transmembrane conductance regulator chloride channel gene prevents ischemic preconditioning in isolated mouse heart. Circulation 2004; 110: 700-4.

27 Duan D. Phenomics of cardiac chloride channels: the systematic study of chloride channel function in the heart. J Physiol 2009; 587: 2163-77.

28 Duan DY, Liu LL, Bozeat N, Huang ZM, Xiang SY, Wang GL, et al. Functional role of anion channels in cardiac diseases. Acta Pharmacol Sin 2005; 26: 265-78.

29 Hume JR, Duan D, Collier ML, Yamazaki J, Horowitz B. Anion transport in heart. Physiol Rev 2000; 80: 31-81.

30 Sheppard DN, Welsh MJ. Structure and function of the CFTR chloride channel. Physiol Rev 1999; 79: S23-S45.

31 Burke MA, Ardehali H. Mitochondrial ATP-binding cassette proteins. Transl Res 2007; 150: 73-80.

32 Gateau-Roesch O, Argaud L, Ovize M. Mitochondrial permeability transition pore and postconditioning. Cardiovasc Res 2006; 70: 264-73.

33 Obal D, Dettwiler S, Favoccia C, Scharbatke H, Preckel B, Schlack W. The influence of mitochondrial $\mathrm{K}_{\text {ATP }}$-channels in the cardioprotection of preconditioning and postconditioning by sevoflurane in the rat in vivo. Anesth Analg 2005; 101: 1252-60.

34 Batthish M, Diaz RJ, Zeng HP, Backx PH, Wilson GJ. Pharmacological preconditioning in rabbit myocardium is blocked by chloride channel inhibition. Cardiovasc Res 2002; 55: 660-71.

35 Diaz RJ, Batthish M, Backx PH, Wilson GJ. Chloride channel inhibition does block the protection of ischemic preconditioning in myocardium. J Mol Cell Cardiol 2001; 33: 1887-9.

36 Heusch G, Liu GS, Rose J, Cohen MV, Downey JM. No confirmation for a causal role of volume-regulated chloride channels in ischemic preconditioning in rabbits. J Mol Cell Cardiol 2000; 32: 2279-85.

37 Heusch G, Cohen MV, Downey JM. Ischemic preconditioning through opening of swelling-activated chloride channels? Circ Res 2001; 89: E48.

38 Riordan JR, Chang XB. CFTR, a channel with the structure of a transporter. Biochim Biophys Acta 1992; 1101: 221-2.

39 Nichols CG. $K_{\text {ATP }}$ channels as molecular sensors of cellular metabo- 
lism. Nature 2006; 440: 470-6.

40 Sheppard DN, Welsh MJ. Effect of ATP-sensitive $\mathrm{K}^{+}$channel regulators on cystic fibrosis transmembrane conductance regulator chloride currents. J Gen Physiol 1992; 100: 573-91.

41 Yamazaki J, Hume JR. Inhibitory effects of glibenclamide on cystic fibrosis transmembrane regulator, swelling-activated, and $\mathrm{Ca}^{2+}$ activated $\mathrm{Cl}^{-}$channels in mammalian cardiac myocytes. Circ Res 1997; 81: 101-9.

42 Duan D, Ye L, Britton F, Miller LJ, Yamazaki J, Horowitz B, et al. Purinoceptor-coupled $\mathrm{Cl}^{-}$channels in mouse heart: a novel, alternative pathway for CFTR regulation. J Physiol (Lond) 1999; 521: 43-56.

43 Kim JA, Kang YS, Lee SH, Lee EH, Yoo BH, Lee YS. Glibenclamide induces apoptosis through inhibition of cystic fibrosis transmembrane conductance regulator (CFTR) $\mathrm{Cl}^{-}$channels and intracellular $\mathrm{Ca}^{2+}$ release in HepG2 human hepatoblastoma cells. Biochem Biophys Res Commun 1999; 261: 682-8.

$44 \mathrm{Kim}$ JA, Kang YS, Lee SH, Lee EH, Lee YS. Role of pertussis toxinsensitive G-proteins in intracellular $\mathrm{Ca}^{2+}$ release and apoptosis induced by inhibiting cystic fibrosis transmembrane conductance regulator (CFTR) $\mathrm{Cl}^{-}$channels in HepG2 human hepatoblastoma cells. J Cell Biochem 2001; 81: 93-101.

45 Xu Y, Krause A, Hamai H, Harvey BG, Worgall TS, Worgall S. Proinflammatory phenotype and increased caveolin-1 in alveolar macrophages with silenced CFTR mRNA. PLoS One 2010; 5: e11004.

46 Valverde MA, Vazquez E, Munoz FJ, Nobles M, Delaney SJ, Wainwright $\mathrm{BJ}$, et al. Murine CFTR channel and its role in regulatory volume decrease of small intestine crypts. Cell Physiol Biochem 2000; 10: 321-8.

47 L'hoste S, Chargui A, Belfodil R, Corcelle E, Duranton C, Rubera I, et al. CFTR mediates apoptotic volume decrease and cell death by controlling glutathione efflux and ROS production in cultured mice proximal tubules. Am J Physiol Renal Physiol 2010; 298: F435-53.
48 Barriere H, Poujeol C, Tauc M, Blasi JM, Counillon L, Poujeol P. CFTR modulates programmed cell death by decreasing intracellular $\mathrm{pH}$ in Chinese hamster lung fibroblasts. Am J Physiol Cell Physiol 2001; 281: $\mathrm{C} 810-24$.

49 L'hoste S, Chargui A, Belfodil R, Duranton C, Rubera I, Mograbi B, et al. CFTR mediates cadmium-induced apoptosis through modulation of ROS level in mouse proximal tubule cells. Free Radic Biol Med 2009; 46: 1017-31.

50 Thevenod F. Multifaceted CFTR: novel role in ROS signaling and apoptotic cell death - a commentary on "CFTR mediates cadmiuminduced apoptosis through modulation of ROS levels in mouse proximal tubule cells". Free Radic Biol Med 2009; 46: 1014-6.

51 Yalcin E, Talim B, Ozcelik U, Dogru D, Cobanoglu N, Pekcan S, et al. Does defective apoptosis play a role in cystic fibrosis lung disease? Arch Med Res 2009; 40: 561-4.

52 Ruiz PE, Ponce ZA, Schanne OF. Early action potential shortening in hypoxic hearts: role of chloride current(s) mediated by catecholamine release. J Mol Cell Cardiol 1996; 28: 279-90.

53 Boujaoude LC, Bradshaw-Wilder C, Mao C, Cohn J, Ogretmen B, Hannun $Y A$, et al. Cystic fibrosis transmembrane regulator regulates uptake of sphingoid base phosphates and lysophosphatidic acid: modulation of cellular activity of sphingosine 1-phosphate. J Biol Chem 2001; 276: 35258-64.

54 Karliner JS. Lysophospholipids and the cardiovascular system. Biochim Biophys Acta 2002; 1582: 216-21.

55 Kunzelmann K. CFTR: interacting with everything? News Physiol Sci 2001; 16: 167-70.

56 Guggino WB, Stanton BA. New insights into cystic fibrosis: molecular switches that regulate CFTR. Nat Rev Mol Cell Biol 2006; 7: 426-36.

57 Wang X, Venable J, LaPointe P, Hutt DM, Koulov AV, Coppinger J, et al. Hsp90 cochaperone Aha1 downregulation rescues misfolding of CFTR in cystic fibrosis. Cell 2006; 127: 803-15. 